Estudios Constitucionales, Año 16, No 1, 2018 pp. 227-244

ISSN 07180195

Centro de Estudios Constitucionales de Chile Universidad de Talca

"Las acciones cautelares y el recurso de protección ¿es necesaria una duplicidad de instituciones? Notas para una mejor garantía de los derechos fundamentales"

Francisco J. Leturia I.

\title{
LAS ACCIONES CAUTELARES Y EL RECURSO DE PROTECCIÓN ¿ES NECESARIA UNA DUPLICIDAD DE INSTITUCIONES? NOTAS PARA UNA MEJOR GARANTÍA DE LOS DERECHOS FUNDAMENTALES*
}

\author{
INJUNCTIONS AND THE RECURSO DE PROTECCIÓN \\ IS A DUPLICATION OF INSTITUTIONS NECESSARY? \\ NOTES FOR A BETTER GUARANTEE OF FUNDAMENTAL RIGHTS
}

FRANCISCO J. LETURIA I.**

Facultad de Derecho, P. Universidad Católica de Chile

Fjleturia@uc.cl

RESUMEN: El Recurso de Protección es una acción cautelar de emergencia establecida para asegurar el respeto y vigencia de derechos fundamentales, que ha gozado de un singular prestigio y un amplio uso en nuestro país. Sostendremos que el Recurso de Protección es un mecanismo cautelar ordinario, reglamentado en forma especial, nacido de las peculiares circunstancias y necesidades existentes al momento de su creación. En la actualidad, podrían adoptarse algunas medidas para que el objetivo que se le ha asignado se realice de mejor manera y en forma más acorde a la institucionalidad general.

ABSTRAC: The "recurso de proteccion" is an emergency action (injunction), established to ensure respect and enforcement of fundamental rights. This tool has enjoyed a unique prestige and a wide use in our country. We will say that the "Recurso de Protección" is an ordinary mechanism of injunction, regulated in a special way, born of the peculiar circumstances and needs existing at the time of its creation. Nowadays, some measures could be taken to ensure that the objective assigned to it, would be carried out better and in a way that is more armonic with the general institutional framework.

PALABRAS claves: Recurso de protección, acciones cautelares, eficacia de la constitución, derechos fundamentales, interpretación.

KEYWORDS: Recurso de protección, injunctions, effectiveness of the constitution, fundamental rights, interpretation.

\footnotetext{
* Artículo recibido el 24 de mayo de 2017 y aprobado el 15 de noviembre de 2017.

** Abogado (PUC). Doctor en Derecho de la Universidad de Salamanca. Profesor de la Facultad de Derecho de la Pontificia Universidad Católica de Chile y Presidente del Centro Nacional de Arbitrajes. Dirección postal: Alameda 340 piso 4 (Facultad de Derecho UC), Santiago de Chile. Dirección electrónica: fjleturia@uc.cl Varios autores (Diez (1999), p. 264; VIVANCO (2004), p. 496; CeA (2004), pp. 629-630).
} 


\section{INTRODUCCIÓN}

El Recurso de Protección es una acción cautelar que tiene por objeto proteger derechos fundamentales frente a posibles "privaciones, perturbaciones o amenazas" de los mismos.

Esta herramienta ha gozado de un singular prestigio en nuestro país y fue, desde muy temprano, señalada como una de las novedades y aportes más importantes de la Constitución de $1980^{1}$. Sin embargo, a nivel comparado, no existen acciones generales de cautela similares, basadas en la aplicación directa e inmediata de los derechos constitucionales ${ }^{2}$, aunque se ofrecen numerosos mecanismos alternativos para asegurar su tutela ${ }^{3}$.

En este trabajo analizaremos si el Recurso de Protección es una acción estructural de nuestro ordenamiento jurídico o si simplemente estamos frente a un mecanismo cautelar ordinario, reglamentado en forma especial.

Asimismo, analizaremos en qué medida su existencia y su relativo prestigio se deben más bien a las necesidades y circunstancias propias del momento de su creación -una acción que permitiera adoptar medidas rápidas y efectivas, en un contexto general de lentitud de la justicia ordinaria- y si ellas se mantienen y justifican en la actualidad.

Finalmente, analizaremos algunas medidas concretas que podrían tomarse para cumplir mejor el objetivo que se ha buscado con su adopción, respondiendo, en última instancia, a la pregunta de qué sucedería a nivel de tutela efectiva de derechos fundamentales, si se recurriera solamente a las posibilidades cautelares ordinarias que ofrece nuestro sistema jurídico, levemente perfeccionadas.

\section{ANTECEDENTES históricos. ¿’POR QUÉ EXISTE EL RECURSO DE PROTECCIÓN?}

Más allá de los aportes concretos realizados por los distinguidos promotores de los proyectos que culminaron en el recurso de protección tal como hoy lo conocemos, esta acción es tributaria de dos procesos históricos confluyentes. El primero de ellos, de carácter global, tiene que ver con la crisis de la cultura legal positivista y su paulatino reemplazo por un "estado constitucional de derecho".

\footnotetext{
1 Varios autores (NAVARRO (2012), p. 616 y Soto Kloss (1982), pp. 24-25) hacen referencia a antecedentes históricos. Pero no parecen ser pertinentes, como lo señala QUINZIO (2001), p. 378.

2 A modo de ejemplo ver Bordalí (2004), p. 278.

3 VIGO (2012), p. 23, citando a Ferrajioli.
} 
El segundo de ellos fue de carácter más nacional, y tiene que ver con el desgaste que fue sufriendo el Estado de Derecho durante el gobierno de la Unidad Popular ${ }^{4}$. Este antecedente es explícitamente reconocido por sus promotores ${ }^{5}, \mathrm{y}$ más allá de la extensión que el adecuado tratamiento del tema requeriría, es que las conductas desafiantes del gobierno de la UP frente al orden legal generaron tensiones, que se vieron reflejadas incluso en reclamos formales de la Corte Suprema y el Congreso Nacional ${ }^{6}$.

Las primeras propuestas para establecer una acción de este tipo, que datan del año 1972, y se fundan en el argumento de que el gobierno podía infringir reiteradamente la Constitución, sin que ella ofreciera los mecanismos adecuados para asegurar su propia eficacia y supremacía ${ }^{7}$.

Pero pocas veces se recuerda que la ausencia de estos mecanismos en la Constitución del 25 no obedeció a un defecto de diseño ${ }^{8}$, sino a un rasgo deseado de un modelo centrado en la ley y en el principio de mayoría, que ya venía haciendo crisis desde hace años, y que ya habían generado en muchos países cambios estructurales que privilegiaban una mayor efectividad de los derechos de rango constitucional.

El Recurso de Protección cristalizó en Chile dicho cambio cultural, que ya había tomado fuerte impulso en toda la Europa de posguerras, y que buscaba dejar a los derechos fundamentales y a la dignidad humana como los elementos centrales del ordenamiento jurídico. Con ello, la regla de la mayoría y el poder del Congreso quedaban limitados mediante la elevación a categoría de normas constitucionales de una serie de derechos generados en un lenguaje propio de la filosofía política y que hasta ese momento sólo "adornaban" algunos textos constitucionales, pero sin pretender tener fuerza jurídica.

Como ya adelantáramos, estas circunstancias se sumaron al agudo malestar existente frente a la lentitud y complejidad de la acción de la justicia, que producía, en la práctica situaciones de denegación de justicia, abuso y malestar social.

\footnotetext{
4 Según Cea (2004), este proceso comenzó en el Gobierno de Eduardo Frei, con la Reforma Agraria p. 707.

5 Soto Kloss (1982), pp. 24-25.

6 Ver, a modo de resumen, el Acuerdo de la Cámara de Diputados, adoptado el miércoles 22 de agosto de 1973 (Sesiones 32 y 33).

7 Varios autores (Soto Kloss (1982), pp. 24-25; Cea (2004), pp. 707-708; Verdugo (1988), p. 5).

8 En contra, CeA (2004), p. 630.
} 
En ese escenario, esta nueva acción cautelar universal, de fácil tramitación y fundamentación, y de respuesta "inmediata", encontró tierra ultra fértil, permitiendo ofrecer un mecanismo de protección altamente efectivo, sin necesidad de modificar los textos legales tradicionales.

\section{El RECURSO DE PROTECCIÓN COMO}

UNA ACCIÓN CAUTELAR ESPECIAL Y LIMITADA

El recurso de protección cumple muchos de los requisitos necesarios para ser considerado una acción cautelar. Estos últimos son elementos remediales necesarios dentro de cualquier sistema procesal orientado a la realización de la justicia en forma efectiva y pragmática? 9

Las medidas anticipadas, cautelares o de tutela (para efectos del análisis que acá realizamos los matices son irrelevantes), permiten asegurar la protección provisional de derechos cuya apariencia es fuerte, sin necesidad de esperar el completo desarrollo del juicio, evitando que su necesaria ritualidad y formalismo termine por privar de la debida protección a los mismos derechos que se busca proteger.

Las medidas precautorias por definición se establecen en forma previa al término del proceso, y generalmente sobre la base de información incompleta. Por ello, es natural que no se les permita declarar derechos permanentes, ni menos ser considerados como una solución que se pueda entregar fácilmente y ante cualquier tipo de circunstancias.

Por el contrario, diremos que la lógica de las medidas cautelares supone:

1.- Que su concesión sea excepcional, y además, mínima ${ }^{10}$, limitándose a aquellos casos en que el bien jurídico afectado sea un derecho especialmente valioso, o cuando la demora en su adopción amenace con afectar significativamente la posibilidad real de dar cumplimiento a la sentencia.

2.- Que de los antecedentes analizados se pueda suponer que tras lo protegido hay al menos algo que tiene la apariencia de un derecho ${ }^{11}$.

4.- Que existe un riesgo o peligro que justifica su adopción, y ciertamente, que la medida considerada sea apta para contrarrestar ese riesgo.

9 Por todos, ver Marín (2006), p. 13. En modo complementario, Peyrano (1981), p. 12.

10 Cortés (2006), p. 529.

11 Ver por todos, OrTells (2000), p. 538. 
5.- Que de entre las medidas que pueden ser adoptadas, se elija la menos gravosa e invasiva, teniendo en consideración la posibilidad de error, y que la existencia cierta del derecho sólo podrá declararse al final del juicio.

6.- Que la urgencia que justifica una medida cautelar supone una flexibilidad procesal y probatoria bastante mayor que la exigida en un proceso ordinario o una sentencia definitiva ${ }^{12}$.

7.- Que las medidas sean transitorias, revisables y sobre todo, corregibles.

De todo lo anterior podemos extraer tres importantes conclusiones:

Primero, que las acciones cautelares no son la vía regia ni la solución óptima de los problemas jurídicos, pese a sus innumerables ventajas y su buen rango de aciertos (estadísticamente analizados), supone también riesgos que recomiendan utilizarlos con cautela.

Segundo, el carácter "accesorio" o instrumental al proceso de toda medida cautelar ${ }^{13}$, que al menos conceptualmente estará asociado a un proceso principal y verdaderamente jurisdiccional, esto es, capaz de producir efecto de cosa juzgada ${ }^{14}$.

Tercero, que el recurso de protección es una acción cautelar sui generis, limitada a la protección de situaciones jurídicas argumentadas en clave iusfundamental, pero que en la práctica puede permitir abordar y resolver cualquier conflicto de relevancia jurídica.

\section{4. ¿Pueden las acciones Cautelares ordinarias CUBRIR EL ESPACIO DEL RECURSO DE PROTECCIÓN?}

Si el recurso de protección puede ser considerado una acción cautelar, la pregunta que surge es si es necesaria una institución autónoma para lograr los objetivos que este se propone, o si mediante algunas reformas procesales menores, o incluso sin ellas, en algunos casos, las acciones cautelares tradicionales podrían satisfacer los mismos.

Hemos señalado que conceptualmente el recurso de protección es una acción cautelar con algunas características específicas con relación a su objeto (limitado a derechos fundamentales, mientras las acciones cautelares en general no tienen

12 CoRTés (2006) p. 541.

13 Ortells (2000) p. 38. Ortells y Calderón (1996) p. 9-10.

14 Sobre el carácter o naturaleza del recurso de protección, (jurisdiccional, acción cautelar, juicio, etc.) ver (Maturana y Mosquera (2010), p. 405; Evans (2006) p. 83; Diez (1999), p. 269) que destacan por su interés y matices las tesis de BORDALí (2004 y 2014). 
esa restricción) y a las facultades que se otorgan al juez y que le permiten tomar las medidas que estime necesarias, y que no se mencionan en forma expresa en la regulación legal de las acciones cautelares (pero que en algunos casos podrían justificarse) $)^{15}$.

$\mathrm{Al}$ igual que cualquier medida cautelar, el Recurso de Protección nos ofrece una sentencia sin efecto de cosa juzgada, y opera con menor formalidad procedimental y probatoria. Su veredicto es obtenido tras un proceso de análisis y balanceo realizado con los antecedentes jurídicos y factuales que se tuvieron a la vista en un breve periodo de tiempo, con el objetivo principal de proteger rápidamente un bien jurídico especialmente relevante.

Hasta acá, las semejanzas entre una acción cautelar ordinaria y el recurso de protección son evidentes, y podemos avanzar bastante preguntándonos en qué posición quedaría un juez a quien se le pide que proteja derechos fundamentales, si el Recurso de Protección no existiera. O en forma análoga, podemos preguntarnos cómo debe enfrentar un juez un reclamo de protección cautelar fundado en derechos fundamentales sólo garantizados, por ejemplo, en tratados internacionales, si llegara a darse el caso.

Frente a ambas preguntas, el texto constitucional nos parece claro, al menos en algunos aspectos.

El inciso $2^{\circ}$ parte final del artículo $5^{\circ}$ de nuestra Constitución ordena a los jueces (a todos los órganos del Estado) respetar y promover los derechos protegidos constitucionalmente, incluyendo en ellos los de Tratados Internacionales ratificados por Chile.

Si consideramos a la Constitución como la cima del ordenamiento jurídico y le atribuimos a sus normas un efecto de irradiación sobre el resto del ordenamiento (o al resto del ordenamiento una función de concreción o materialización de la Constitución), debemos suponer que las leyes explicitan la Constitución, y que por lo mismo, al aplicar las leyes correctamente, se aplica también la Constitución.

El juez además tiene un mandato expreso de proteger y promover los derechos fundamentales. Por tanto, no puede sino interpretar las normas conforme al sistema de fuentes señalado por el artículo $5^{\circ}$ inciso $2^{\circ}$, aun a falta de texto legal

15 Un punto interesante que no podrá ser desarrollado en este trabajo acá son las medidas cautelares que coincidan o incluso superen la demanda principal. CALAMANDREI ya se refería a ellas como medidas anticipativas. Calamandrei (1945) p. 56. En un contexto más contemporáneo, CorTés las critica, aunque reconoce su complejo tratamiento doctrinario y las necesidades de la vida económica actual. CoRTÉs (2006), pp. 530 y ss. 
expreso en tal sentido. Sólo al hacerlo de este modo cumplirá adecuadamente con el mandato constitucional.

Podrá cuestionarse que nadie sabe a ciencia cierta el alcance de la expresión "respetar y promover" a que hace referencia el artículo $5^{\circ}$, pero lo que parece a todas luces claro es que los jueces están especialmente llamados a materializar los objetivos y principios constitucionales, especialmente encarnados en aquellos derechos "que emanan de la naturaleza humana".

Así las cosas, enfrentados a un caso concreto, los jueces deberán dictar las providencias que estén a su alcance cuando de ello dependa asegurar la vigencia de un derecho fundamental. Al final de cuentas, estamos hablando de los bienes y derechos más valiosos y dignos de protección y tutela de todo nuestro sistema legal.

Sería legítimo plantearse la pregunta de si es que la argumentación legal permitiera dar protección al derecho, esta debiera preferirse a la de base constitucional, considerando además que ella es mucho más precisa y concreta, y que incorpora y materializa a la Constitución, siendo de algún modo una expresión de la misma.

Asimismo, podría plantearse la duda de si en este propósito, el juez que conoce de una acción cautelar está facultado para ir más allá de lo solicitado por las partes, asumiendo un rol más protagónico en la correcta identificación del derecho afectado o de la medida a adoptar, impidiendo que la impericia del reclamante termine disminuyendo la protección de los derechos vinculados a la dignidad humana, al menos en los casos más extremos. Si consideramos que el mandato de respetar y promover los derechos fundamentales forma parte de las "bases de la institucionalidad", este punto no debiera generarnos mayores problemas (criterio válido también para los casos de protección), sobre todo si no estamos refiriéndonos a una sentencia definitiva (cosa juzgada).

Así las cosas, pareciera que las acciones cautelares podrían permitir cubrir razonablemente los espacios y necesidades actualmente ocupados por el recurso de protección, casi sin que para ello se requieran grandes cambios normativos. En efecto, en casi todo lo no señalado, pareciera que deben seguirse los criterios generales de la protección cautelar, que en Chile siempre han tenido una comprensión amplia y flexible, equilibrada por la lógica de la "mínima afectación" o "mínima intervención” (el artículo 298 del Código de Procedimiento Civil se refiere a un poder cautelar amplio, aunque infrarregulado y susceptible de mejoras) ${ }^{16}$.

$\overline{16}$ En el mismo sentido, CoRTÉs (2006), p. 534. 


\section{5. ¿ES EN LA ACTUALIDAD EL RECURSO DE PROTECCIÓN UN MECANISMO IDÓNEO Y ADECUADO?}

Cuando fue creado, el recurso de protección fue considerado masivamente como un progreso significativo. Eso es un hecho objetivo.

Cuarenta años después, con un sistema jurídico bastante más sofisticado y un nivel de desarrollo institucional y económico muy superior al existente en los años 70, parece posible plantear ajustes que permitan lograr los mismos objetivos, favorezcan su mejor funcionamiento y permitan una institucionalización más armónica de esta herramienta con el resto del ordenamiento jurídico. El proceso de reflexión en torno a la reforma de la constitución, podría ser una buena instancia para reflexionar sobre este punto.

Para ello, intentaremos identificar los principales problemas o efectos colaterales no deseados que esta acción ha significado o puede generar, tanto por sí misma como en su implementación.

Sin que el orden implique una prioridad, y asumiendo el riesgo de ser reiterativos para privilegiar la claridad, haremos un intento.

1.- La adopción de soluciones jurisdiccionales que nacen de la aplicación directa de la Constitución menosprecia la importancia y necesidad de la función/ solución legislativa, empobreciendo el debate político y dificultando la precisión y correcta delimitación del contenido de los derechos.

2.- La ambigüedad e indeterminación jurídica que caracteriza a las normas constitucionales puede debilitar, cuando se intenta aplicarlas en forma directa, las necesidades de certeza y seguridad jurídica que toda sociedad y toda economía requieren (y que toca precisamente al sistema jurídico garantizar).

3.- El fundamento constitucional de una decisión judicial, que no solo considera derechos sino que también principios y valores, ofrece amplios espacios para el activismo y la discrecionalidad judicial ${ }^{17}$. Además, impone al juez una obligación de justificar su fallo en una forma que estamos muy lejos de haber observado en la práctica nacional.

4.- La lentitud de los procedimientos comunes es un problema serio, y no sabemos cuánto el Recurso de Protección haya contribuido a la demora en su abordaje. Ofreciendo una solución de emergencia, especialmente diseñada para los casos más graves, ha permitido ocultar el problema y postergar su solución.

17 GarCía y Verdugo (2013). Estos autores señalan que algunas formas de activismo judicial suponen una amenaza para el sistema democrático. 
5.- Los conflictos entre derechos de rango constitucional (o mejor dicho, entre pretensiones jurídicas incompatibles amparadas y argumentadas en un discurso de base ius fundamental), reflejan las diferencias más profundas de cualquier sociedad, por lo que su decisión requiere la máxima legitimidad política, dentro de los canales adecuados para ello. La preferencia de la honra sobre la libertad de expresión, o de la autonomía reproductiva de una mujer violada sobre la vida del feto, por ejemplo, no pueden quedar entregadas al arbitrio de un grupo de jueces, sino que deben ser abordados como asuntos de interés y competencia colectiva. Por lo mismo, requieren un análisis y una decisión institucional y política, y no judicial.

6.- El Recurso de Protección muchas veces se desarrolla en situaciones jurídicas que exigirían una justificación muy seria y completa de los criterios adoptados, sobre todo ante situaciones no normadas o donde hay un conflicto, real o aparente, entre derechos constitucionales. Pero la fuerte tradición legalista de nuestra cultura jurídica, sumado al aún importante número de casos de protección que cada año se presentan (más allá de la distorsión cuantitativa de los reclamos contra las Isapres en los últimos años), ha favorecido un deficiente sistema de argumentación, que se complementa entrópicamente con una jurisprudencia muchas veces zigzagueante.

7.- El Recurso de Protección, más que un juicio, es una acción cautelar. No puede quedar establecida como la vía regia para la solución de los problemas jurídicos más delicados de nuestra vida social ${ }^{18}$.

8.- El aumento del poder de la judicatura en desmedro del poder legislativo, que podría observarse con un uso más expansivo de esta herramienta constitucional, importaría una profunda reestructuración de la distribución de poderes, que ni la Constitución ni la comunidad política han querido.

Para evitar constituirse, por la vía del recurso de protección, en "el señor del derecho", la Corte Suprema y la práctica de las Cortes de Apelaciones han restringido, de hecho, el acceso a este recurso, en una práctica que para algunos es un acto de prudencia y realismo, y para otros, una limitación impropia y abusiva de las acciones ofrecidas por la Constitución.

18 CeA (2004), p. 631. Advirtiendo sobre los riesgos MARín (2006), p. 14. 
También puede ser una mezcla de ambas, pues aunque en el fondo esta restricción puede ser razonable, efectivamente importa una serie de decisiones y criterios más propios de una norma legal, que de un "auto acordado" 19.

En esto, los tribunales son víctimas de un doble vínculo.

Si aceptan todos los recursos de protección, se convierten en "los señores del derecho", haciendo colapsar el sistema jurídico y al diseño constitucional.

Si los restringen, asumen facultades que no les son propias (legislativas) y limitan, entre pocos y sin previo aviso, las posibilidades ofrecidas por una acción constitucional.

En cambio, si tocase a los actores políticos asumir esta disyuntiva, podrían gestionar cambios institucionales y los recursos económicos necesarios para ello, en una arena propia del mundo político, donde a la Corte Suprema le está vedado actuar.

Por todo ello, al final del día, la creciente reducción del uso de este mecanismo, por vía de los Autos Acordados, ha llevado a que más de algún autor señale a la Corte Suprema como la responsable de la "lenta agonía" del Recurso de Protección ${ }^{20}$.

\section{6. ¿QUÉ SOLUCIONES SE HAN ENCONTRADO A PROBLEMAS SIMILARES EN OTROS ORDENAMIENTOS JURÍDICOS?}

Las problemáticas arriba descritas han comenzado a ser advertidas y poco a poco a ser criticadas por la doctrina, sobre todo a la luz de la experiencia comparada, que se ha enfrentado a problemas similares y ha encontrado formas igualmente eficientes y menos costosas de satisfacer los mismos objetivos.

No es este el espacio adecuado para realizar una reconstrucción histórica de la expansión de la órbita de la eficacia de los derechos fundamentales hacia las relaciones entre particulares ni de la posibilidad de invocar directamente la Constitución en sede judicial.

La generalidad de los países, independientemente de su historia o tradición, hoy aplican sistemas de eficacia indirecta, pero toman medidas para asegurar que el contenido material de la constitución no sea letra muerta y alcance al mayor tipo de relaciones posibles.

19 Bruna (1998), pp. 131-135.

20 Saenger (1998), p. 271 y Cerda (2001), pp. 399-340. 
Muchas veces, el énfasis de estos mecanismos en el control de los actos del Estado es mayor, y se evita interferir con la vida contractual y la lógica de la autonomía de la voluntad, salvo en los casos más serios y de mayor gravedad. De esta manera se evita el riesgo de que cada infractor recurra a los tribunales para cuestionar la validez de cada contrato, argumentando su insensibilidad frente a algún derecho constitucional.

Al mismo tiempo, esta salida permite y privilegia el desarrollo legislativo frente al desarrollo jurisprudencial de los Derechos Fundamentales, aunque dejando espacios para el funcionamiento complementario de ambas. De alguna manera, este juego ofrece un doble sistema de garantía de la eficacia material de la constitución: una a nivel general (normativa) y otra a nivel particular (judicial).

Nuestro país se plantea frente a estas posibilidades en forma contradictoria.

Por un lado, establece constitucionalmente un recurso que podría permitir la implementación de un modelo pleno de eficacia horizontal y directa de las garantías constitucionales (pero al mismo tiempo permite a la Tercera Sala de la Corte Suprema que por medio de un acuerdo de sus integrantes limite su acceso, favoreciendo a ratos la práctica un modelo más bien tradicional o legalista).

Al mismo tiempo, por otro lado la Constitución obliga a todos los órganos del Estado, y por tanto a los jueces, a proteger y promover los derechos garantizados por la Constitución (artículo $5^{\circ}$ inciso $2^{\circ}$ ), lo que no es otra cosa que un clásico modelo de eficacia indirecta o mediata de la Constitución, al estilo alemán.

Dicho en otras palabras, la parte final del artículo $5^{\circ}$ inciso $2^{\circ}$ recién citado, obliga al juez a velar por la eficacia real de los derechos constitucionales, por lo que cada vez que conoce un caso o interpreta una ley, aun sin que las partes lo pidan, debe tener en mente la necesidad de que tanto la norma como la solución se ajusten a la Constitución (como a los tratados internacionales que versen sobre la misma materia). Los beneficios técnicos de este método son importantes, evitando, de paso, entrar en la escolástica discusión sobre la naturaleza jurídica, rango y ejecutabilidad de las convenciones internacionales.

\section{Bases PARA UnA PROPUESTA DE MODERNIZACIÓN Y} PERFECCIONAMIENTO DEL RECURSO DE PROTECCIÓN

Nuestra propuesta es sencilla.

Buena parte de los derechos fundamentales han sido explicitados y desarrollados por normas infraconstitucionales, típicamente de rango legal y luego de un 
largo y riguroso proceso de deliberación política. Por muchas razones (precisión, certeza, regulación de situaciones particulares, entre otras), conviene que así sea.

En presencia de estas reglas, muchas vulneraciones de derechos fundamentales podrían ser argumentadas y resueltas en armonía con la Constitución desde la normativa legal, específicamente concebida para dicha situación, sin forzar al juez a echar mano a la vaguedad e imprecisión propia de un texto fundamental (nacional o internacional).

De esta manera, por ejemplo, si un vecino corriera el deslinde de su propiedad y afectara nuestro derecho, junto con invocar el artículo 19 de la Constitución, deberemos mencionar las normas y acciones ofrecidas por el Código Civil (derecho de dominio, propiedad inscrita, acción reivindicatoria, o la que corresponda).

Sabemos que nuestro sistema procesal ofrece la posibilidad de impetrar acciones precautorias, incluso en forma previa a la interposición de la demanda, que permitirán al juez adoptar las medidas que juzgue convenientes para "reestablecer el imperio del derecho"21.

Bien utilizados, estos mecanismos específicos, comunes y masivos, podrían ser suficientes para la completa protección del derecho fundamental afectado, perturbado o amenazado 22 .

Además, por razones de número y geografía, la protección por la vía de tribunales ordinarios facilitaría el acceso a la justicia y la protección de los actores en situación más precaria.

El artículo $5^{\circ}$ inciso $2^{\circ}$ también es fruto del proceso de constitucionalización del derecho. Como hemos ya señalado, esta última disposición ordena a los jueces aplicar la ley a la luz y orientación de los derechos fundamentales, permitiendo que se haga realidad el principio de supremacía constitucional.

Ello permite garantizar la real efectividad de los derechos y la correcta aplicación de las normas, por medio de su comprensión desde la Constitución.

Si los jueces de primera instancia cumplieran con lo dispuesto por esta norma constitucional, es decir, si al aplicar la ley el juez siempre aplicara al mismo tiempo la constitución que le da fundamento, cualquier acción cautelar o precautoria podría servir exactamente para los mismos objetivos que el recurso de protección.

Aunque con una gran diferencia: al presentar su solicitud de cautela, el actor ya no invocará directamente o necesariamente la Constitución y sus amplios

21 Marin (2004), p. 257.

22 CoRTés (2006), p. 534. 
derechos, sino que argumentará sobre la base de las normas legales, dictadas para dar desarrollo y precisar el contenido de los derechos constitucionales, ofrecer seguridad a los actores sociales y facilitar la labor jurisdiccional.

Si el juez, directamente obligado por la constitución, entiende la ley de la forma en que la constitución le obliga a hacerlo (aun en ausencia de petición de parte), la protección de los derechos parece asegurada.

Para todos los casos en que exista una ley específica (y más allá de la utopía de la completitud del derecho), la acción de protección deberá presentarse ante el juez de primera instancia como medida precautoria (prejudicial o no, según cada caso), evitando así que hasta la más mínima y reglamentada diferencia jurídica sea fundada directamente en la Constitución o conocida por las Cortes de Apelaciones.

En cambio, aquellas situaciones que no cuenten con un desarrollo legislativo suficiente podrían ser reservadas para ser vistas por un tribunal colegiado, y revisadas, mediante la apelación, por la Corte Suprema. En ningún caso sería necesario eliminar el recurso de protección tal como lo hemos conocido hasta hoy.

Si se reserva el acceso a las Cortes de Apelaciones/Recurso de Protección sólo a solicitudes de especial relevancia (por estar fundadas directamente sobre el texto constitucional, por ejemplo), se refuerza la idea de que el espacio idóneo para tomar decisiones normativas que suponen opciones políticas es el Congreso, lo que no obsta a la acción complementaria y subsidiaria que puedan hacer los Tribunales. Al mismo tiempo, se refuerza la idea de que la sumisión del juez es ante todo a la ley (que materializa lo ordenado por la Constitución) y no a la Constitución directamente (pese a la ley o a quien sea).

Alguien podría argumentar que "la protección de los derechos fundamentales es algo tan serio y relevante, que por lo mismo, no puede quedar entregado al libre arbitrio de los políticos. Para la protección de los derechos que emanan de la naturaleza humana, ofrecen más garantía de corrección, prudencia y justicia nuestros jueces que nuestros políticos".

Ante el estado actual de cosas, este argumento puede producir algún eco, como parece haberlo producido durante los años 70 . Pero aceptarlo como solución permanente supondría eludir la verdadera causa del problema, renunciando a buscar una mejora de nuestra vida política, socavando el modelo político adoptado y la propia Carta fundamental.

Las democracias constitucionales suponen órganos diferentes para el autor de la ley y su ejecutor. Un órgano legislativo y otro judicial, cada uno con objetivos y con diseños estructurales distintos, y con mecanismos recíprocos de control. 
Un mundo donde todos los problemas son resueltos en forma jurisprudencial, sobre la base de un breve listado de derechos y con prescindencia de normativas más específicas, no es posible ni conveniente. Las Cortes de Apelaciones no son el lugar donde radicar las principales disputas políticas, siempre vinculadas con la determinación de los alcances, contenidos y límites de los derechos fundamentales.

Quedaría por responder algunas preguntas propias del orden procesal, pero que son de menor relevancia para el objetivo que nos hemos trazado. La determinación o exigencia o no de cauciones (así como cualquier mecanismo para desincentivar la litigación frívola o instrumental), la necesidad de interponer la demanda principal dentro de cierto plazo (aun cuando la parte afectada por la medida no lo reclame), o la legitimación para interponer esta acción cautelar de protección, son algunos de los detalles que deberán atenderse cuando se tome la decisión de dar este paso.

\section{Conclusiones}

1.- El objeto de este artículo es promover una modernización y perfeccionamiento del recurso de protección, a la vez que ampliar su ámbito de aplicación. Para ello, básicamente proponemos que cuando una materia cuente con regulación infra constitucional, el recurso de protección sea conocido por el juez ordinario para ese asunto, como una medida cautelar cualquiera, prejudicial o judicial, según corresponda.

2.- Además de masificar y facilitar la tutela judicial de los derechos fundamentales, la fórmula planteada permitiría remarcar la superioridad y preferencia de la ley en cuanto a fuente de la solución jurídica, entendiendo que ella materializa a las disposiciones constitucionales y la ajustan en cada situación concreta.

3.- Asimismo, en virtud de lo dispuesto en el artículo quinto inciso segundo, los órganos del Estado deben promover y proteger los derechos expresados en la Constitución, por lo que todo juez, a la hora de revisar cualquier acción prejudicial precautoria, debe promover el respeto de los derechos fundamentales, aun cuando no se lo soliciten en forma expresa.

Una solución de este tipo, que reitera a los jueces de primera instancia su obligación de entender el derecho integrando la Constitución y la ley (que hasta ahora no se aprecia), facilitará la vigencia de los derechos fundamentales y favorecerá la toma de conciencia respecto a los profundos cambios que implica y ha implicado el proceso de constitucionalización del derecho. 
4.- Así entendida, no hay mayor diferencia operativa entre el recurso de protección y la de una medida precautoria. Con algunos ajustes procesales menores, todos los beneficios del recurso de protección podrían ser obtenidos de la mano de una acción cautelar ordinaria.

5.- La solución planteada tiene ventajas de economía procesal (será el mismo juez quien conozca la medida cautelar y la eventual acción de fondo) y de acceso a la justicia (hay más jueces que Cortes de Apelaciones, están más atomizadas geográficamente y sólo requieren de un juez). Al igual como sucede con el recurso de protección, es posible que muchos casos terminen con la medida precautoria, no siendo necesario desarrollar la totalidad del juicio, si la parte "vencida" no lo requiere dentro de un plazo razonable. Asimismo, la posibilidad de establecer cauciones permitirá disminuir la litigación frívola o instrumental.

6.- Esta forma de tramitar la acción cautelar de protección como una acción precautoria, obligaría al solicitante a utilizar una argumentación de origen legal, aunque con trasfondo constitucional. Ello alejaría el fantasma de la eficacia directa, más allá de la evidente conveniencia técnica de precisar y delimitar los derechos constitucionales que debe hacerse en sede legislativa, para aumentar la certeza y seguridad jurídica y abordar adecuadamente situaciones específicas.

7.- El cambio propuesto no conlleva la sugerencia de que convenga eliminar el actual Recurso de Protección, ni menos quitarle su rango legal. Sólo que se reservará el acceso a la sede de apelación a aquellas materias que no cuenten con una regulación legal específica. Tampoco implica eliminar el Recurso de Amparo.

Adicionalmente, se podría utilizar la ubicación actual del Recurso de Protección, para estructurar nuestro planteamiento, para lo cual bastaría con un breve párrafo.

8.- El modelo presentado aumentará la protección de los derechos y robustecerá el rol del Congreso y de la ley. Asimismo, evitará a los Tribunales enfrentar situaciones incómodas y que en ningún caso han buscado, como asumir la reglamentación procesal de este recurso o resolver, sin una regla clara, asuntos políticos discutidos y altamente sensibles, como típicamente ocurre con los conflictos entre derechos fundamentales (activismo judicial, etc.).

9.- Finalmente, es necesario decir que la propuesta acá realizada no puede entenderse como una propuesta fundamental. Sólo busca llevar la mirada hacia ciertas ideas y planteamientos, y reflexionar sobre las posibilidades de los mismos. Luego, en los ajetreos propios del juego político, se valorará la conveniencia de adoptar, en determinado momento u otro, una solución diferente. Al final del día, lo que realmente buscamos es la existencia de un sustrato de reflexión y 
conocimiento suficiente, que permita adoptar las medidas que posibiliten una adecuada protección de los derechos fundamentales, dentro de un contexto de orden institucional. Todo ello, sabiendo que no existen modelos perfectos, y que toda decisión, en uno u otro sentido, tendrá dificultades, limitaciones y costos.

\section{BiBLIOGRAFÍA CITADA}

Bordalí Salamanca, Andrés (2004): "El Recurso de Protección como proceso de urgencia", Revista Chilena de Derecho (vol. 31, No 2), pp. 269-288.

Bordalí Salamanca, Andrés (2014): "El Recurso de Protección, todavía un fantasma jurídico", Revista de Derecho (Valdivia), (vol. 27, № 2), pp. 277-283.

Bruna Contreras, Guillermo (1998): "Los autos acordados de la Corte Suprema sobre el Recurso de Protección", Revista Chilena del Derecho, (Número Especial), pp. 131-135.

Calamandrei, Piero (1945): Introducción al estudio sistemático de las providencias cautelares (Traducc. Santiago Sentis Melendo, Buenos Aires, Editorial Bibliográfica Argentina).

Cea Egaña, José Luis, (2004): Derecho Constitucional Chileno. Deberes derechos y garantías. (Santiago, Ediciones Universidad Católica de Chile) Tomo II.

Cerda Quinteros, Victoriano (2001): "La muerte del Recurso de Protección", Revista de Derecho Público, (vol. 63, 2001), pp. 380-401.

Cortez Matcovich, Gonzalo (2006): "Eficacia del procedimiento civil y la técnica de las medidas cautelares". En GarCía G., José Francisco; LetUria I., Francisco Javier y SiLva, José Pedro (Editores): Justicia Civily Comercial, Una Reforma Pendiente. Bases para el Diseño de la Reforma Procesal Civil. (Santiago de Chile, Ediciones Libertad y Desarrollo), pp. 521-553.

Diez UrzÚA, Sergio (1999): Personas y Valores, su protección constitucional, (Santiago, Editorial Jurídica de Chile).

Evans EspiÑeira, Enrique (2007): La Constitución Explicada, (Santiago, Ediciones LexisNexis).

García G., José Francisco y Verdugo, Sergio (2013): Activismo judicial en Chile ¿hacia el gobierno de los jueces? (Santiago, Ediciones Libertad y Desarrollo).

MaRín, Juan Carlos (2006). "Las medidas cautelares en el ordenamiento jurídico chileno: su tratamiento en algunas leyes especiales". Revista de Estudios de la Justicia, (8), pp. 13-37. 
Maturana, Cristián, y Mosquera, Mario (2010): Los Recursos Procesales, (Santiago, Editorial Jurídica de Chile).

Navarro Beltrán, Enrique (2012): "35 años del recurso de protección. Notas sobre su alcance y regulación normativa", Estudios constitucionales (vol. 10 No 2), pp. 617-642.

Ortells Ramos, Manuel y Calderón Cuadrado, María Pía (1996): La tutela judicial cautelar en el derecho español (Granada, Editorial Comares).

Ortells Ramos, Manuel (2000): Las medidas cautelares (Madrid, Ediciones La Ley).

Peyrano, Jorge W. (1981): Medida cautelar innovativa. (Buenos Aires, Editorial Desalma).

Quinzio Figueiredo, Jorge Mario (2001): "Recurso de Protección: Reivindicación Histórica Constitutional", Revista de Derecho Público, (No 63), pp. 375-379.

SAENGER, Fernando (1998): "La lenta agonía del recurso de protección". Revista Chilena de Derecho, (Número Especial), pp. 259-27.

Soto KLoss, Eduardo (1982): El Recurso de Protección, (Santiago, Editorial Jurídica de Chile).

VIGo, Rodolfo Luis (2012): Constitucionalización y judicialización del derecho, (Bogotá, Ediciones Universidad Javeriana).

Vivanco Martínez, Ángela (2004): Curso de Derecho Constitucional. Aspectos Dogmáticos de la Carta Fundamental de 1980 (Santiago, Ediciones Universidad Católica de Chile) Tomo II. 